\title{
Coupled DEM-FDM simulation of cone penetration tests in coarse grained soils
}

\author{
Mussie Kidane ${ }^{1 *}$, Andrés Alfonso Peña Olarte ${ }^{2}$, and Roberto Cudmani ${ }^{2}$ \\ ${ }^{1}$ Federal Waterways Engineering and Research Institute (BAW), Wedeler Landstrasse 157, 22559 Hamburg, Germany \\ ${ }^{2}$ Center for Geotechnics, Technical University of Munich, Franz-Langinger-Str. 10, 81245 Munich, Germany
}

\begin{abstract}
The numerical modelling of geotechnical problems often poses major challenges when large displacements and strain localization are involved. Conventional continuum mechanical approaches like the finite element method (FEM) or the finite difference method (FDM) suffer from mesh distortion and numerical inaccuracy when large deformations are involved. In addition, they require the use of appropriate constitutive models to simulate the soil behaviour. The distinct element method is a promising alternative for large deformation analyses. It does not have the limitations resulting from the numerical discretization of the continuum- and not need a constitutive model since the macroscopic response results from the individual particle interaction. However, the maximum number of particles and therefore the domain of the simulation is nowadays limited by the available computational capacity. To overcome this limitation, a coupled DEM-FDM approach is proposed used to optimize the number of particles for a combined numerical domain consisting of areas of large and small displacements. The performance of the coupled DEM-FDM approach is investigated by simulating cone penetration tests in coarse grained soils.
\end{abstract}

\section{Introduction}

Simulating geotechnical boundary-value problems can cause major challenges when large displacements are involved as in the case of debris flow, soil-structure interaction during pile installation and soil liquefaction. Classical numerical approaches based on the continuum theory as the finite element method (FEM) and the finite difference method (FDM) are affected by mesh distortion and numerical inaccuracy when large deformations are involved. Advanced versions of these methods to deal with large deformations do exist but are often not commercially available or need extensive user expertise when used for the aforementioned class of problems [1]. A promising alternative for the numerical analysis of such problems is the distinct element method. Thereby, instead of assuming that the granular skeleton is a continuum, the individual particles are modelled and therefore there are no limitations regarding the deformation [2, 3]. However, the computation effort and time increase with the number of particles limiting the total number of particles that can be modelled with the commonly available computer capacity. To overcome this limitation a coupled DEMFDM, in which discrete elements are used in the largedeformation zone and a continuum is assumed outside this zone. To apply this approach the software packages PFC3D [4] for the discrete elements and FLAC3D [5] for the continuum will be combined. The main goal of this contribution is the implementation of a tool for the numerical solution of large deformation problems in geotechnical engineering, such as pile installation and cone penetration in coarse granular soils using coupled DEM/FDM analyses. In this contribution the perspectives of a coupled analyses will be shown by simulations of the cone penetration test (CPT).

\section{Cone penetration test for in-situ investigations}

The mechanical characterisation of soil deposits is of central importance for the civil engineering and mining industry. Construction sites and reservoirs need to be explored and characterised depending on a number of aspects like soil type, particle size, density, among others.

The soil mechanical characterisation of soil deposits using the cone penetration test (CPT) is a standard practice worldwide. Thereby, a cone is pushed with a constant penetration rate into the ground while the reaction forces at the tip and the sleeve are measured. The CPT is commonly used to indirectly determine the density in coarse granular soil deposits, where retrieving undisturbed samples is often not feasible with a reasonable effort. As the cone resistance depends on granulometric properties of the soils and the state variables (density, effective pressure, fabric, cementation) different correlations have been proposed in practice to estimate classical shear strength and stiffness parameters from the cone resistance [6].

* Corresponding author: mussie.kidane@baw.de

A video is available at https://doi.org/10.48448/pkmf-1y98 


\section{Numerical methods}

We use "Particle Flow Code in 3 Dimensions" PFC3D (DEM) to model the granular soil in the near field of the CPT cone [4]. The commercial code FLAC3D "Fast Lagrangian Analysis of Continua in 3 Dimensions" software based on the finite difference method (FDM) [5], is used here to simulate the far field interactions between the CPT cone and the granular soil.

\subsection{Model conditions}

The model consists of a cylindrically shaped combined DEM-FDM domain consisting of an outer FDM-domain and an inner DEM-domain. The DEM model consists of spheres and walls, see Fig. 1. Spheres can interact with each other and the walls through mechanical contact interaction laws. Here a linear elastic contact law is employed. The motion of the walls is slaved to that of the FDM nodes, and forces exerted on the walls are transferred as externally applied forces (i.e., boundary conditions) to the FDM nodes. The CPT is modelled using continuum (FDM) elements only. Model dimensions for the CPT are $D=35.6 \mathrm{~mm}$ (diameter), $L=655.25 \mathrm{~mm}$ (total length) $\alpha=60^{\circ}$ (angle of the conical tip) matching the CPT dimensions of the of a $10 \mathrm{~cm}^{2}$ cone as defined in [[7]] see also Table 1.

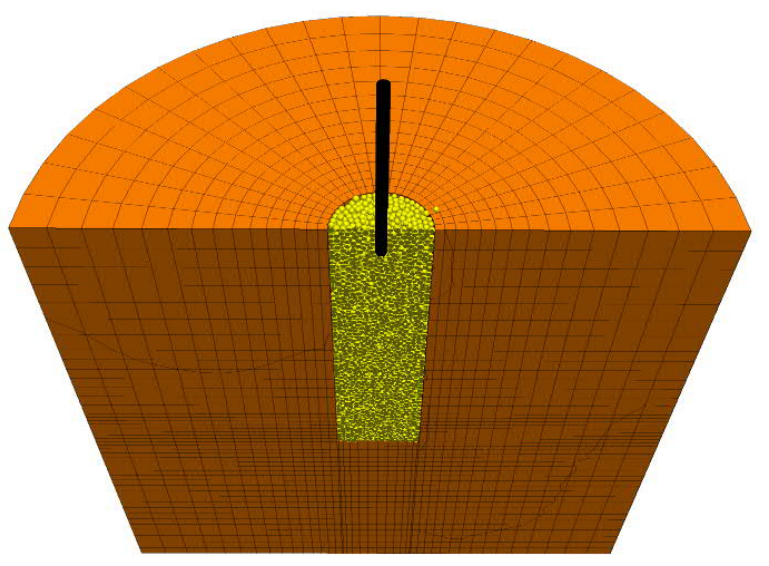

Fig. 1. Coupled model with cutting plane through center in vertical direction CPT in black, DEM in yellow and FDM in orange.

\subsubsection{DEM model validation}

The contact model was chosen as it has a very simple structure which reduces the number of variables during parameter calibration. Results of a back calculation of triaxial tests on a glacial fine sand from Lueneburg (D), are depicted in Fig. 2.

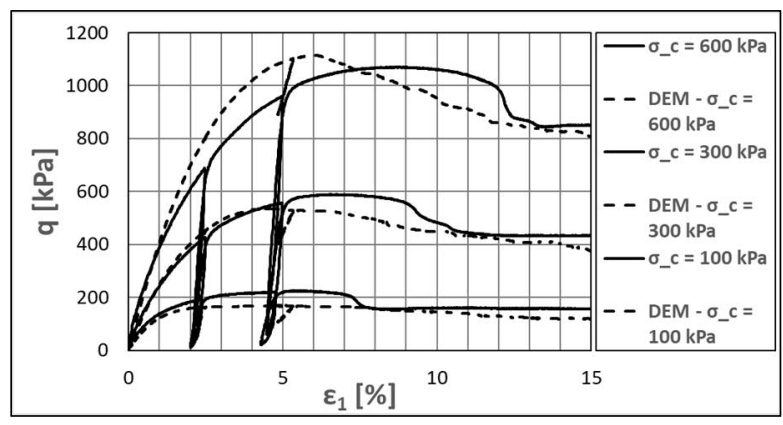

Fig. 2. Comparison of deviator stress $(q)$ over axial strain $\left(\varepsilon_{l}\right)$ for drained triaxial tests (isotropic consolidation with a confining stress of $\sigma_{c}$ ). DEM-model consists of 2846 spheres - cubic cell with periodic boundaries.

\subsubsection{Model Setup}

The model consists of approx. 25,000 spherical particles and 5,440 zones. The particle size is chosen in accordance to a specified grain size distribution of a glacial sand deposit from the construction site of the ship lock in Lueneburg, Germany [8]. The grain size distribution depicts a rather narrow range of grain sizes. The particles have been scaled up in order to reduce number of particles and the simulation times, see Fig. 3.

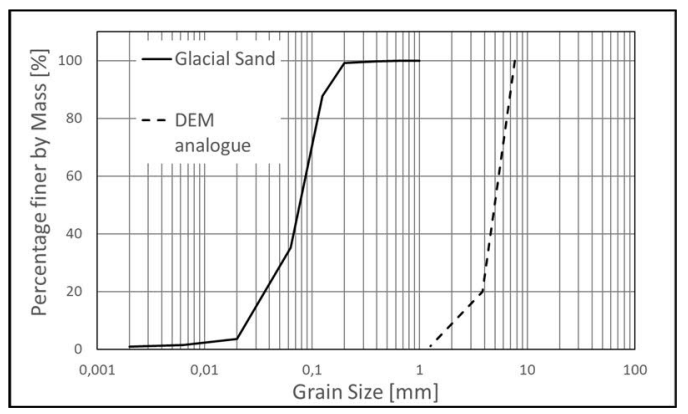

Fig. 3. Grain size distributions of glacial sand the DEM analogue.

The dimensions of the model should reproduce those of a calibration chamber [9] of large dimensions which is used to approximate field test conditions and develop correlation methods for practical applications. A detailed investigation on the use of DEM for simulation of calibration chamber tests (without coupling to FDM) can be found in [10]. Particle scaling by a factor of approx. 50 was applied while keeping distance in the radial direction next to the CPT in the order of 15 times the diameter of the medium particle size $\left(D_{50}\right)$. This setup should ensure a large strain deformation mode with a shear band within the DEM domain $[11,12]$.

Since we are coupling a continuum with a discrete domain to model the same granular material, the mechanical behaviour of both domains shall be identical. Nonetheless, the strict fulfilment of this "homogeneity" condition is impossible, since continuum and discrete models will improbably predict "exactly" the same mechanical behaviour and coupling the domains will always introduce numerical heterogeneity up to some extent. In our current simulations, we have used a linear-elastic material to 
model the continuum and therefore, the homogeneity condition is clearly violated. An improvement of the coupled model shall be achieved by using advanced constitutive models for granular materials and making homogeneity tests, e.g. the simulation of the element tests to quantify the heterogeneity introduced by coupling the domains.

Table 1. Dimensions of the DEM-FDM model.

\begin{tabular}{|c|c|}
\hline Diameter of the FDM-Model & $2200 \mathrm{~mm}$ \\
\hline Height of the FDM-Model & $1800 \mathrm{~mm}$ \\
\hline Diameter of the DEM-Model & $186.7 \mathrm{~mm}$ \\
\hline Height of the DEM-Model & $450 \mathrm{~mm}$ \\
\hline Diameter of the CPT-Cone & $36.5 \mathrm{~mm}$ \\
\hline Angle of the conical tip & $60^{\circ}$ \\
\hline Total Length of the CPT-Shaft & $655.25 \mathrm{~mm}$ \\
\hline
\end{tabular}

\section{Validation of the model on a field test and analysis of results}

In order to verify this coupled FDM/DEM model, a CPT of a site investigation campaign for the ship lock in Lueneburg (Germany) was simulated and compared with field test results.

The site comprises a number of different soil types like glacial till and clay which are not the subject of this contribution. The lowest layer (grey zone in Fig. 4) though consists of a glacial fine sand with CPT tip resistance in the range of $55 \mathrm{MPa}$ and a CPT sleeve resistance of approx. 0.6 MPa, see Fig. 4.

As the sand layer to be investigated is located below an elevation of $45 \mathrm{~m}$ below ground level, an overburden stress of $450 \mathrm{kPa}$ is approximated through a surface load at the top of the combined DEM-FDM-soil domain. As a first approximation, the displacements at the outer boundary of the continuum domain are constrained in radial direction.

Table 2. Final parameter set for the DEM-FDM model, for definition of parameters see $[4,5]$.

\begin{tabular}{|l|l|l|}
\hline Entity & $\begin{array}{l}\text { Material } \\
\text { Model }\end{array}$ & Parameters \\
\hline $\begin{array}{l}\text { Properties of the } \\
\text { FDM Model }\end{array}$ & Linear Elastic & $\begin{array}{l}\text { E-Module }=54.365 \mathrm{MPa} ; \\
v=0.25 ; \rho=10 \mathrm{kN} / \mathrm{m}^{3}\end{array}$ \\
\hline $\begin{array}{l}\text { Properties for the } \\
\text { sphere-sphere } \\
\text { contacts }\end{array}$ & $\begin{array}{l}\text { Linear Contact } \\
\text { Model }\end{array}$ & $\begin{array}{l}\text { Emod }=54.365 \mathrm{MPa} ; \\
\text { kratio }=1,5 ; \text { fric }=0.4\end{array}$ \\
\hline $\begin{array}{l}\text { Properties for the } \\
\text { FDM-DEM } \\
\text { interface }\end{array}$ & $\begin{array}{l}\text { Linear Contact } \\
\text { Model }\end{array}$ & $\begin{array}{l}\text { kn }=0.5 \mathrm{e} 5 ; \text { kratio }=1,0 ; \text { fric } \\
=0.5 ; d p \_ \text {nratio }=0.2\end{array}$ \\
\hline $\begin{array}{l}\text { Properties for the } \\
\text { CPT-sphere } \\
\text { interface }\end{array}$ & $\begin{array}{l}\text { Linear Contact } \\
\text { Model }\end{array}$ & $\begin{array}{l}\text { Emod }=54.365 \mathrm{MPa} ; \\
\text { kratio }=1,5 ; \text { fric }=0.55\end{array}$ \\
\hline
\end{tabular}

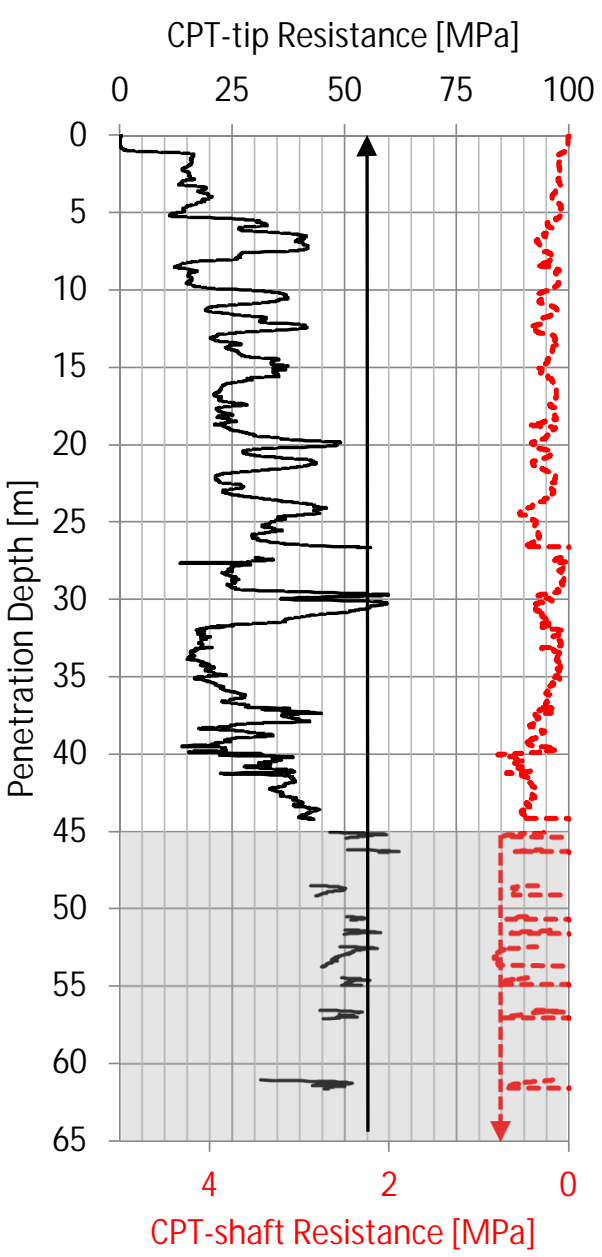

Fig. 4. CPT-tip (black/left) and -shaft (red/right/dotted line) resistance of a field test in Lueneburg, Germany using a 10 $\mathrm{cm}^{2}$ cone; grey shaded - investigation area.

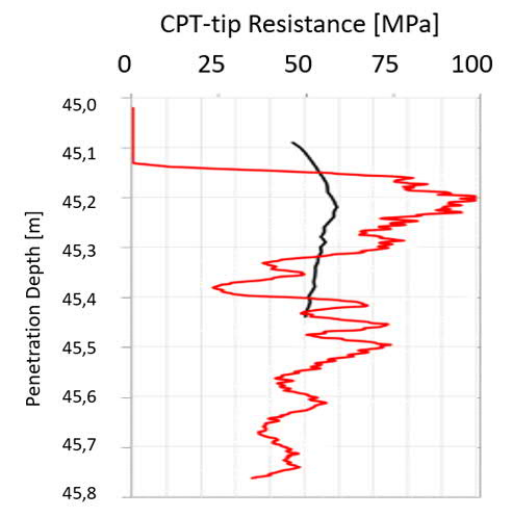

Fig. 5. Measured CPT-tip resistance (black) and computed CPT-tip resistance (red).

The simulations show a strong dependence of the cone and shaft resistance on the particle friction and stiffness. On the contrary, the outer continuum domain is placed far enough from the cone and its influence on the results is negligible. The size of the DEM domain was not varied during the calculation. Its influence on the numerical results shall be investigated in more detail.

The comparison of the measurements and calculations show a good agreement for the cone 
resistance (averaged computed 53.5 MPa against 55 $\mathrm{MPa}$ measured value, see also Fig. 5), but poor prediction for the shaft resistance (computed $0.1 \mathrm{MPa}$ against $0.6 \mathrm{MPa}$ measured value). Required improvements of the model are addressed in chapter 5 .

\section{Discussion and outlook}

Preliminary simulations of the CPT in coarse-grained soils were carried out using a novel approach, in which the granular material is modelled by coupling a nearfield Discrete Element domain (DEM) with a far-field continuum domain (FDM). On the one side, the computing time can be considerably reduced in comparison with a DEM simulation with the same domain size. On the other side, large deformations occurring near the cone can be better captured by the coupled Domain than in purely continuum models.

Further investigations are ongoing to clarify several aspects of the numerical simulation and improve the approach:

- Influence of the heterogeneity induced by the domain coupling.

- Implementation of advanced constitutive models as [13].

- Influence of the boundary conditions of the FDM model domain, as these will affect the results in a manner that a stress controlled lateral boundary results in lower CPT-resistances as a rigid lateral boundary $[14,15]$.

- Detail calibration of the particle contact model (linear and nonlinear) with triaxial including different stress paths.

- Influence of the boundary conditions and size of the DEM model domain. So far, the interface conditions have been chosen by trial and error, trying to achieve a nearly continuous displacement pattern at this interface. The behaviour of this interface influences the stress pattern and the fabric of the DEM domain and needs to be better understood.

- Mechanisms of shear localization and particle breakage in the near field.

- Influence of particle shape by using polyhedral and clumps.

The abovementioned investigations will increase the predictive capability of the numerical model and will enable a more fundamental understanding of the mechanisms governing the cone penetration and other similar processes as pile jacking and driving.

Advice on the use of FLAC3D by Oscar Javier Moreno Cediel from BAW is gratefully acknowledged.

\section{References}

[1] D. Wang, B. Bienen, M. Nazem, Y. Tian, J. Zheng, T. Pucker, M.F. Randolph, Large deformation finite element analyses in geotechnical engineering, Comp. and Geot., 65, April, 104-114 (2015)
[2] P.A. Cundal, R.D. Hart, Numerical Modelling of Discontinua, Engineering Computations, 9, 2, 101-113 (1992)

[3] P.A. Cundal, O.D.L. Strack, A discrete numerical model for granular assemblies, Géotechnique, 29, 1, 47-65 (1979)

[4] PFC - Particle Flow Code, Ver. 6.0., Itasca Consulting Group Inc., Minneapolis, Minnesota, USA (2020).

[5] FLAC3D - Fast Lagrangian Analysis of Continua in 3 Dimensions, Ver. 7.0., Itasca Consulting Group Inc., Minneapolis, Minnesota, USA (2020)

[6] T. Lunne, P.K. Robertson, J. Powell, Cone Penetration Testing in Geotechnical Practice, Spon Press/Taylor \& Francis Group, New York, USA (1997)

[7] DIN Deutsches Institut fuer Normung, DIN EN ISO 22476-1 - Geotechnical investigation and testing - Field testing - Part 1: Electrical cone and piezocone penetration test, Berlin, Germany (October, 2013)

[8] U. Matthiesen, M. Pohl, R. Rother, S. Henke, Geotechnical challenges in the design of the new Lueneburg lock next to the existing ship lift, in Proceedings of the $19^{\text {th }}$ ICSMGE, 17-22 September 2017, Seoul, South Korea (2017)

[9] M. Jamiolkowski, D.C.F. Lo Presti, M. Manassero, Evaluation of relative density and shear strength of sands from CPT and $D M T$, In Soil behavior and soft ground construction, ASCE Geotechnical Special Publication 119, 201-238 (2003)

[10] J. Butlanska, Cone Penetration Test in a Virtual Calibration Chamber, Phd. Thesis, Universitat Polytècnica de Catalunya (2014)

[11] K.H. Roscoe, The influence of strains in soil mechanics, $10^{\text {th }}$ Rankine Lecture, Géotechnique, 20, 2, 129-170 (1978)

[12] H.B. Muehlhaus, I. Vardoulakis, The thickness of shear bands in granular materials, Géotechnique, 37, 3, 271-283 (1987)

[13] Y.F. Dafalias, M.T. Manzari, Simple plasticity sand model accounting for fabric change effects. J. Eng. Mech. 130, 6, 622-634 (2004)

[14] M. Jamiolkowski, C.C. Ladd, J.T. Germaine, R. Lancellotta, New developments in field and laboratory testing of soils, Proceedings of the $11^{\text {th }}$ International Conference on Soil Mechanics and Foundation Engineering, 12-16 August 1985, San Francisco, California, USA (1985)

[15] P.W. Mayne, F.H. Kulhawy, Calibration chamber database and boundary effects correction for CPT data. Proceedings of the $1^{\text {st }}$ International Symposium on Calibration Chamber Testing, 28-29 June 1991, Potsdam, New York, USA (1991) 